\title{
Prepared for practice? UK Foundation Doctors' confidence in dealing with ethical issues in
}

the workplace

\section{BACKGROUND}

A foundation year doctor (FY) is a grade of medical practitioner in the United Kingdom (UK) undertaking the Foundation Programme: a two-year postgraduate medical training programme rotating between specialities which forms the bridge between medical school and specialist/general practice training. FY1 doctors are new graduates in their first year of work; FY2 doctors are in their second year of work. Foundation training was introduced in 2005 and is designed to give trainees a range of general experience and further training before choosing an area of medicine in which to specialise.[1] A curriculum for the Foundation Programme was developed in 2005 and has been updated over the years.[2]

\section{INTRODUCTION}

It has been consistently reported in the literature that high percentages of FY doctors feel underprepared in general to begin working in a hospital.[3-5] The General Medical Council (GMC) found that $30 \%$ of qualifying doctors did not feel adequately prepared.[6] This may be a particular problem in the area of medical ethics and law (MEL): Jones reported that junior doctors were less well prepared than in other areas when they faced making a decision involving ethical and legal issues.[7] Findings from a recent qualitative analysis supported this: 'new graduates were relatively unprepared for ethical and legal aspects [of work]' especially in the areas of resuscitation decisions, discharge against medical advice, confidentiality concerns when a patient brought in by the police and cases involving domestic violence.[8]

Ethical issues are commonplace in daily clinical practice and the ability to assess and deal with these is a generic skill needed by all doctors from their first day of work (albeit it with appropriate supervision). However, research suggests that FY doctors have trouble dealing with ethical issues they encounter in practice.[9-13] There is a world of difference between discussing ethical problems in the relative safety of a seminar and acting ethically when the implications of a decision suddenly become real. Furthermore, MEL educators of junior doctors report variability in ethical knowledge among doctors.[14]

This paper aims to provide further insight into the self-reported preparedness and confidence of FY doctors in making MEL related decisions. Whilst self-reporting by the junior doctor may not be a full assessment of adequate preparation, concerns about lack of preparedness are not only subjectively reported by the doctors themselves.[15] Matheson surveyed senior members of the medical hierarchy (registrars and consultants) who supervised FY doctors and found that the seniors deemed FY doctors somewhat underprepared to faced medico-legal and ethical issues, but felt it important that FY doctors were prepared in matters surrounding limits of competence, maintaining confidentiality, probity, and protecting patients' rights.[10] 


\section{METHODS}

The main aim of the study was to identify the MEL training needs of FY doctors in the UK by using an on-line survey answered by FY doctors in both their first and second Foundation year. We also hoped to understand what FY doctors need in terms of ethics training to support them in their current role, whilst also appreciating that their perceptions of current needs is likely to be influenced by their previous training.

An online survey was sent to all FY1 and FY2 doctors across the UK over a six-week period between February and March 2018. These months were selected to ensure FY doctors had gained at least six months of experience in their new role.[16] Responses were anonymous and participation was voluntary. Basic demographic data was recorded including age, gender and stage of foundation training.

The respondents were asked 'Following medical school to what extent did you feel prepared to respond to the MEL challenges of being a Foundation Doctor?' and responded to this on a visual scale of 0 to $100 \%$ by dragging a marker to the appropriate point.

The respondents were then given three ethically challenging clinical scenarios (see Appendix). They were not asked to make a decision about the scenario, but to score their perceived confidence in handling the situation on a scale of one to five. The cases were designed to be of increasing complexity with the aim of examining confidence in responding to ethical issues, but also to assess for awareness of the FY doctors' limitations and need to ask for help. Indeed, the third case was purposely made sufficiently complex that it would tax most senior clinicians. Furthermore, the clinical cases were used in a research capacity, rather than to teach and learn the ethical dimensions of medicine. We accept that using cases in research, like all data collection approaches and methods, are not perfect and have strengths and limitations . [17-19]

The approach to data collection and the content of the survey were developed following engagement with key stakeholders from the British Medical Association, General Medical Council, Health Education England, and UK Foundation Directors Committee. We recognised the challenges when attempting to engage FY doctors in research such as time away from clinical duties, and shift patterns. We therefore opted to conduct an online survey that we designed to be completed quickly and easily on a computer or mobile phone. It also enabled us to gather a broader range of perspectives across a larger geographical area. The survey was tested by two members of the research team, who were FY doctors at the time of testing. Statistical analysis was performed using the R software application.[20]

Ethical approval was obtained from the research ethics committee of the Faculty of Health and Medicine at Lancaster University and from Health Education England. The survey was promoted with support from the UK Foundation Programme and the Institute of Medical Ethics. 
As with other studies involving FY doctors, the main limitation of our study relates to the generalisability of the findings.[21] Approximately three percent of all UK FY doctors completed the survey; a similar response rate to that of other studies involving FY doctors. [22, 23] As noted from previous researchers, junior doctors are a notoriously difficult group to encourage to complete questionnaires.[24] A concern of low response rates in surveys is response bias; it is considered that respondents differ in their views compared to nonrespondents.[10, 22, 23, 25] In order to meet the research aims, we have not linked the findings to either medical school or Foundation School when analyzing our data. While we accept that this could be considered a limitation of our study, the wide range of medical and Foundation schools attended by our respondents prohibited meaningful analysis. Despite the limitations, the present study does provide a valuable snapshot of opinions from hundreds of FY doctors, which are a notoriously hard-to-reach population. Future research may wish to consider using qualitative approaches such as focus groups in order to provide more in-depth exploration of the topic.

\section{RESULTS}

479 FY doctors completed the survey, of whom approximately $45 \%$ were FY1s and approximately 55\% FY2s. In 2018 there were 14,785 doctors in Foundation training in the UK giving a response rate of 3.2\%. [26] Further demographics of the respondents are shown in table 1.

Table 1: Demographic profile of respondents

\begin{tabular}{|l|l|l|l|}
\hline Variables & Values & Observations & Percentages \\
\hline Age & Under 20 & 1 & $0.21 \%$ \\
\hline & $20-24$ & 136 & $28.4 \%$ \\
\hline & $25-29$ & 292 & $60.96 \%$ \\
\hline & $30-34$ & 30 & $6.26 \%$ \\
\hline Gender & $35-39$ & 10 & $2.09 \%$ \\
\hline & $40+$ & 6 & $1.25 \%$ \\
\hline & Prefer not to say & 4 & $0.83 \%$ \\
\hline & Female & 308 & $64.3 \%$ \\
\hline
\end{tabular}




\begin{tabular}{|l|l|l|l|}
\hline & Male & 158 & $33 \%$ \\
\hline & Prefer not to say & 13 & $2.7 \%$ \\
\hline Career Stage & F1 & 218 & $45.5 \%$ \\
\hline & F2 & 254 & $53 \%$ \\
\hline & Prefer not to say & 7 & $1.5 \%$ \\
\hline
\end{tabular}

\section{Feeling prepared for MEL challenges}

204 FY1 doctors answered the question about the extent to which they felt prepared to respond to the MEL challenges of being a FY doctor (see figure 1). Their mean average preparedness was $63.16 \%$ (median $65 \%$, mode $75 \%$ ) with a standard deviation of 18.95 . Thus there is a large range of preparedness among the respondents with $68.2 \%$ giving preparedness values between 44 and $82 \%$ and $95.4 \%$ giving values between 26 and 100\%. Pearson's second skewness coefficient (median skewness) is -0.50 , indicating that a number of respondents provided preparedness values towards the extreme lower end of the scale, that is they were not very prepared, but the majority reported higher levels of preparedness, as indicated by the median (65\%) and mode (75\%) averages.

$231 \mathrm{FY} 2$ doctors replied to this question (see figure 2). Their mean average preparedness (63.54\%) was almost identical to that of the FY1 doctors, as was the median (68\%) and mode (70\%). Again the standard deviation of 18.12 indicates a large range of self-reported preparedness ( $68.2 \%$ of respondents gave preparedness values between $45-82 \%$, and $95.4 \%$ gave preparedness values between 27-100\%). Pearson's second skewness coefficient (median skewness) is -0.91 , again indicating a number of respondents provided preparedness values towards the extreme lower end of the scale (not very prepared for MEL challenges at qualification), but the majority reported high levels of preparedness, as indicated by the median (68\%) and mode averages (70\%).

\section{Preparedness by gender}


284 female doctors and 143 male doctors answered this question. Female median preparedness was $65 \%$ (interquartile range of 25 ) and male $70 \%$ (interquartile range of 26.5). The unpaired two-sample Wilcoxon Test indicates that female respondents report significantly lower preparedness than their male counterparts $(p=0.025)$.

\section{Preparedness by FY year}

$204 \mathrm{FY} 1$ doctors and $231 \mathrm{FY} 2$ doctors answered this question. Median preparedness for the FY1s was 65\% (interquartile range of 25.2) and for the FY2s 68\% (interquartile range of 24.5). The unpaired two-sample Wilcoxon Test did not show a significant difference between year of Foundation training and self-reported preparedness at time of qualification $(p=0.84)$.

\section{Self-reported confidence in approaching three ethically challenging cases}

Table 2 summarises the level of reported confidence in approaching the three cases. The doctors were asked to select the response most appropriate to their level of confidence from five options:

1. Not at all

2. I can recognise some issues, but cannot evaluate their importance in this case

3. I can recognise and weigh the ethical issues but cannot reach a decision in such cases

4. I can work through the ethics and make a plan but I am not confident

5. I am confident that I can make an ethically reasoned decision

An earlier section of the survey asked both about training on MEL topics on which the respondent had been taught at medical school and on which they would like training as an FY. The responses to the relevant topics are included in table 2.

Table 2: Self-reported confidence in approaching three complex cases

\begin{tabular}{|l|l|l|l|}
\hline & $\begin{array}{l}\text { Confidentiality } \\
(\mathbf{n}=399)\end{array}$ & $\begin{array}{l}\text { Self-discharge } \\
(\mathbf{n}=398)\end{array}$ & $\begin{array}{l}\text { Withdrawal of } \\
\text { nasogastric feeding } \\
(\mathbf{n}=398)\end{array}$ \\
\hline Not at all & $5(1.25 \%)$ & $14(3.51 \%)$ & $8(2.01 \%)$ \\
\hline $\begin{array}{l}\text { I can recognise } \\
\text { some issues, but } \\
\text { not evaluate their } \\
\text { importance in this } \\
\text { case }\end{array}$ & $8(2.01 \%)$ & $9(2.26 \%)$ & $13(3.27 \%)$ \\
\hline
\end{tabular}




\begin{tabular}{|l|l|l|l|}
\hline $\begin{array}{l}\text { I can recognise and } \\
\text { weigh ethical issues } \\
\text { but cannot reach a } \\
\text { decision in such } \\
\text { cases }\end{array}$ & $84(21.05 \%)$ & $93(23.37 \%)$ \\
\hline $\begin{array}{l}\text { I can work through } \\
\text { the ethics, make a } \\
\text { plan, but I am not } \\
\text { confident }\end{array}$ & $229(57.39 \%)$ & $163(40.85 \%)$ & $160(40.20 \%)$ \\
\hline $\begin{array}{l}\text { I am confident that } \\
\text { I can make an } \\
\text { ethically reasoned } \\
\text { decision }\end{array}$ & $73(18.30 \%)$ & $142(35.59 \%)$ & $124(31.16 \%)$ \\
\hline $\begin{array}{l}\text { Numbers of those } \\
\text { who answered the } \\
\text { case who were } \\
\text { taught topic at } \\
\text { medical school }\end{array}$ & $377(94.49 \%)$ & $141(35.43 \%)$ & $247(62.06 \%)$ \\
\hline $\begin{array}{l}\text { Numbers of those } \\
\text { who answered case } \\
\text { who would like } \\
\text { training on the } \\
\text { topic during FYs }\end{array}$ & $121(30.33 \%)$ & $288(72.36 \%)$ & $261(65.58 \%)$ \\
\hline
\end{tabular}

Seventeen (4.3\% of those who answered all 3 cases) FY doctors answered that they were fully confident to make an ethically reasoned decision in all five cases. Of these, 11 were FY2 doctors and two had a postgraduate level qualification in medical ethics. Eight were female and all but one were under 30 years of age.

$40 \mathrm{FY}$ doctors of the 398 respondents to all three cases (10\%) answered 'not at all' or 'I can recognise some issues here but cannot evaluate their importance in this case' to one or more case. Of these, 28 (70\%) were female and 17 (42.5\%) were in their first foundation year. None had a higher degree in medical ethics.

Only one FY doctor answered 'not at all' to all three cases. Three respondents answered 'not at all' or 'I can recognise some issues here but cannot evaluate their importance in this case' to all 3 cases. Of particular interest, six of those who answered the cases were unable to 
evaluate the issues in the first (confidentiality) case but were able to make a plan or were confident in one or both of the more complex cases.

\section{Confidence in approaching the cases and desire for FY training in the relevant topic}

Fisher's Exact Test was used to assess whether those who were relatively underconfident in approaching the case (that is, answered 1-3) were more likely to want further training in the relevant area in their FY years than those who were more confident (answering 4 or 5 ). There was no significant difference in this for any of the three cases apart from training on mental health ethics and law, but it was those with a higher level of confidence in approaching the case who wanted teaching on this at FY level (see table 3).

Table 3: Confidence in approaching the cases and desire for FY training on the relevant topic

\begin{tabular}{|l|l|l|l|}
\hline Case & $\begin{array}{l}\text { Answer 1-3 (less } \\
\text { confident) }\end{array}$ & $\begin{array}{l}\text { Answer 4 or 5 (more } \\
\text { confident) }\end{array}$ & Fisher's Exact Test \\
\hline Confidentiality & $\begin{array}{l}n=97 ; 35(36.1 \%) \\
\text { want teaching }\end{array}$ & $\begin{array}{l}\mathrm{N}=301 ; 86(28.6 \%) \\
\text { want teaching }\end{array}$ & $\begin{array}{l}\mathrm{P}=0.16 \text { (not } \\
\text { significant) }\end{array}$ \\
\hline $\begin{array}{l}\text { Discharge against } \\
\text { medical advice } \\
\text { (DAMA) with a } \\
\text { mental health } \\
\text { aspect }\end{array}$ & $\begin{array}{l}\mathrm{n}=93 ; 69 \text { (74.2\%) } \\
\text { want teaching on } \\
\text { DAMA }\end{array}$ & $\begin{array}{l}\mathrm{n}=303 ; 219 \text { (72.3\%) } \\
\text { want teaching on } \\
\text { DAMA }\end{array}$ & $\begin{array}{l}\mathrm{P}=0.82 \text { (not } \\
\text { significant) }\end{array}$ \\
\hline $\begin{array}{l}\text { Withdrawing } \\
\text { nasogastric feeding }\end{array}$ & $\begin{array}{l}\mathrm{n}=113 ; 74 \text { (65.5\%) } \\
\text { want teaching }\end{array}$ & $\begin{array}{l}\mathrm{n}=282 ; 187 \text { (66.3\%) } \\
\text { want teaching }\end{array}$ & $\begin{array}{l}\mathrm{P}=0.96 \text { (not } \\
\text { significant) }\end{array}$ \\
\hline $\begin{array}{l}\text { mental health ethics } \\
\text { mant }\end{array}$ & $\begin{array}{l}\text { want teaching on } \\
\text { mental health ethics }\end{array}$ & $\begin{array}{l}\mathrm{P}<0.0001 \text { (highly } \\
\text { significant) }\end{array}$ \\
\hline
\end{tabular}

\section{DISCUSSION}

Our results raise two key issues. Firstly, some graduating doctors are not adequately prepared to deal with the complex ethical and legal issues they will encounter and some of those who 
are not confident do not recognise that they need further training or support. Secondly and conversely some may be overconfident, do not recognise their limitations and may also therefore not seek help when it is needed.

\section{The 'underprepared' graduate}

The GMC in 'Outcomes for Graduates 2018' requires that at qualification doctors can '...apply ethical reasoning to situations which may be encountered in the first years after graduation.'[27] However, it is an unrealistic aim to expect FY doctors to be fully confident in managing all complex ethical scenarios. Such confidence comes with seniority and experience and even then many cases remain a challenge. Our study has shown that mean self-reported preparedness is $63 \%$. Given the complexity of many modern ethical challenges this seems at first glance to be reasonable. $44.6 \%$ of FY1s and $46.3 \%$ of $\mathrm{FY} 2 \mathrm{~s}$ in this study were selfreportedly $70 \%$ or more prepared for MEL issues in the workplace. This is similar to the findings by Miles that over $50 \%$ of FY1 doctors are well prepared to deal with ethical, legal and safety issues.[28] However, 43 (21.1\%) of the FY1s and 35 (15.2\%) of FY2s in this study felt less than $50 \%$ prepared to face MEL challenges. Furthermore, we designed the cases with the expectation that a competent newly qualified doctor would as a minimum be able to work through the case and make a plan, albeit not confidently, in the confidentiality case. However, 97 (24.3\%) failed to meet this proposed standard. The challenge for educators, both at undergraduate and postgraduate level, is to identify and support these underprepared doctors. It seems that teaching a topic at medical school only goes part way to prepare FY doctors for practice. $94 \%$ of respondents to our survey had been taught on confidentiality at medical school, yet $30 \%$ wanted further training and at least $24 \%$ (those who were unable to make a reasoned plan in the case as above) need it. It seems that those who are selfreportedly not confident in making an ethical decision are not more likely than those who are confident to want postgraduate training on the relevant topic.

Many junior doctors claim that the teaching in medical school can be too theoretical and would like more practical clinical teaching. [24] Whilst this was within the context of clinical aspects of medical school training, the 'real life' application of knowledge gained could hold relevance for MEL too. Ethics curricula have often been 'top down', structured in relation to abstract bioethical principles, rather than by trainee experiences and self-identified educational needs, representing a more 'bottom up' approach.[29] Perhaps this goes some way to explaining the higher than expected confidence in the nasogastric withdrawal of feeding case. Nearly two thirds of respondents had had training on this at medical school but maybe this was theoretical and they had not had the opportunity to apply their learning to a real case and therefore did not see the true complexities of the case. Conversely maybe the FY doctors had seen the (possibly more frequently encountered) confidentiality issues in their jobs and had become less confident than they would have been immediately on graduation as the difficulties of applying the theoretical to an individual case became crystallised by experience. 


\section{The 'overconfident' graduate?}

Fourteen (6.9\%) of FY1s and nine (3.9\%) of FY2s in our study reported that they were $90 \%$ or more prepared to face MEL challenges at graduation with a further 71 (16.3\%) being selfreportedly $80-89 \%$ prepared. The second and third cases were designed to be particularly complex and probably beyond the decision-making skills of most FY doctors. However, more FY doctors were fully confident in the more complex cases than in the confidentiality case, with approximately a third stating they were confident in decision-making in the second and third cases. It is possible that this was simply a gut response done quickly on smart phones and that the complexities may be more obvious in real life, but it is likely that there is a degree of naivety; the inexperience of FY doctors means they do not know what they do not know, leading to a degree of overconfidence.

Confidence and competence are not the same in the eyes of the junior doctor.[30] The relationship between the two is complex: it can be both positive (confidence increases as competence increases) and inverse (confidence decreases as competence increases).[30] Therefore, we must exercise a degree of caution in interpreting our results relating to confidence in approaching the cases, particularly as the FY doctors' interpretation of confidence may differ from ours.[30]

There is support from other authors that FY doctors can be overconfident. In one study seniors found FY doctors to be underprepared or inexperienced at specific (clinical) tasks or making decisions whilst being overconfident.[21] Junior doctors (residents) in an American study were more likely to be overconfident than students or seniors in clinical decision making; when the FY-equivalent was confident in the diagnosis they were incorrect $15 \%$ of the time.[31] A literature review by Berner has shown that, although experts by definition are more knowledgeable than novices, novices tend to overrate their skills: the individuals with the lowest skill levels overestimate their performance.[32]

Those making ethical decisions may be at risk of premature closure: a concept defined by Berner as 'narrowing the choice of diagnostic hypotheses too early in the process, such that the correct diagnosis is never seriously considered'. The premise behind this is that once an adequate solution is found we stop seeking alternative (and possibly better) solutions.[32] Junior doctors may well be at particular risk of this when their inexperience means they cannot see all the real-life implications and complexities of a case. If a decision fits a moral framework they may accept this and state they are confident in their decision, particularly in a classroom (or survey) exercise. This may be exacerbated if there appears to be a legally correct' answer.

In the light of this, we need to consider what is required to prepare students and junior doctors for MEL challenges. Appropriate curricular content at medical school may help, as may teaching sessions for FY doctors on medical ethics.[33] However, this alone will not ensure our junior doctors are ethically competent. [34] We can discourage a tick-box 
approach to ethics and reduce the gap between real-life ethics and curricula by running sessions in which students/trainees bring their own cases and experience of encountering ethical issues, and by encouraging reflective practice. [35-37] However, without a doubt, making good ethical decisions comes with wisdom and experience, albeit based on adequate knowledge and the development of good communication skills. Virtues such as wisdom cannot be simply learned in the undergraduate years: these develop with appropriate thought and consideration over years of practice. [38] Part of training junior doctors to make ethically considered decisions needs to be an appropriate environment which includes senior support, the ability for juniors to speak up and ask questions, an interested community of clinicians, awareness of the importance of the hidden curriculum, and attention to the stresses that junior doctors face.[35, 39] It is well-reported that tiredness, fear and lack of support can adversely impact on decision-making.[40, 41]

\section{Conclusion}

A high proportion of FY doctors have reasonable levels of self-reported preparedness for MEL issues and confidence in dealing with complex ethical cases. However, recently qualified doctors can be vulnerable when facing ethical decisions in the workplace by being underprepared, not recognising their lack of ability to make a reasoned decision or by being overconfident. The latter two vulnerabilities are perhaps the most concerning as these doctors may well not seek further training, support or ask for help in making these complex decisions.

Undergraduate and postgraduate educators need to be aware of this and provide practical MEL training based on trainee experiences and real-world ethics and challenge learners' views as well as delivering the core areas of an ethics curriculum. Training in MEL topics should not be viewed as a one-off event but should be revisited and built upon. Therefore, undergraduate and postgraduate training need to be viewed in partnership, with foundation training viewed and received as an extension of the learning at medical school. Clinical supervisors for FY doctors also need to be sensitive to the needs of their FY juniors and not only watch for the underperforming or underprepared FY doctor, but also the overconfident FY doctor who may equally be unsafe.

However, we need to be clear what the expectation should be for ethical preparedness for graduates and junior doctors. Given the complexities of many ethical decisions, we should not see preparedness as the ability to make (or confidence in making) a difficult decision but rather a recognition that such cases are difficult, that doubt is permissible and the solution may well be beyond the relatively inexperienced doctor. Medical school and junior doctor educators and supervisors should therefore be ensuring that this is clear to their trainees: while the expectation on graduation for cardiopulmonary resuscitation, for example, must be true competency, for an ethical decision the appropriate level may well be recognising that one does not know the 'answer'. Of course, this then leads to the requirement for an 
environment in which questions can be asked and uncertainty raised with the expectation of a supportive response.

\section{REFERENCES}

1. Collins J. Foundation for excellence: an evaluation of the foundation programme. London: Medical Education England. 2010 https://www.copmed.org.uk/publicationsarchive/foundation-for-excellence accessed 12/10/2019.

2. Kirkham $D$ and Baker P. Twelve tips for running teaching programmes for newly qualified doctors. Med Teach 2012;34:625-630.

3. Goodfellow PB and Claydon P. Students Sitting Medical Finals-Ready to be House Officers? J R Soc Med 2001;94(10):516-520.

4. Hannon FB. A national medical education needs' assessment of interns and the development of an intern education and training programme. Med Educ 2000;34(4):275-84.

5. Promes SB, Chudgar SM, Grochowski CO et al. Gaps in Procedural Experience and Competency in Medical School Graduates. Acad Emerg Med 2009;16:S58-S62.

6. General Medical Council. The state of medical education and practice in the UK. 2014 https://www.gmc-uk.org/-/media/documents/SOMEP 2014 FINAL.pdf 58751753.pdf accessed 12/10/2019.

7. Jones A, McArdle PJ and O'Neill PA. How well prepared are graduates for the role of pre-registration house officer? A comparison of the perceptions of new graduates and educational supervisors. Med Educ 2001;35(6):578-584.

8. Monrouxe LV, Bullock A, Gormley G et al. New graduate doctors' preparedness for practice: a multistakeholder, multicentre narrative study. BMJ Open 2018;8:e023146. doi:10.1136/bmjopen-2018-023146.

9. Illing J, Morrow, G, Kergon C et al. How prepared are medical graduates to begin practice? A comparison of three diverse UK medical schools. Final report to the General Medical Council. 2008 https://www.gmc-uk.org/-/media/about/how-preparedare-medical-graduates.pdf?la=en\&hash=07C74B365A0626BFC35D8B3F09D37D6C32C30957 accessed 12/10/2019.

10. Matheson $C$ and Matheson D. How well prepared are medical students for their first year as doctors? The views of consultants and specialist registrars in two teaching hospitals. Postgrad Med J 2009;85(1009):582-589.

11. O'Neill PA, Jones A, Willis SC et al. Does a new undergraduate curriculum based on Tomorrow's Doctors prepare house officers better for their first post? A qualitative study of the views of pre-registration house officers using critical incidents. Med Educ 2003;37:1100-1108.

12. Shibu PK, Subramonian S, Suresh M et al. Junior doctors' awareness of terminology relating to key medico-legal and ethical principles: a questionnaire survey. Clin Med (Lond) 2008;8:231-232.

13. Vivekananda-Schmidt $P$ and Vernon B. FY1 doctors' ethicolegal challenges in their first year of clinical practice: an interview study. J Med Ethics 2014;40:277-281.

14. Sokol D, Doyal L and Doyal L. Ethics, law, and the junior doctor. Postgrad Med J 2010;86:629-630. 
15. Eva KW and Regehr G. Self-assessment in the health professions: A reformulation and research agenda. Acad Med 2005;80(10 Suppl):S46-S54.

16. Byrne D, Buttrey $S$, Carberry $C$ et al. Is there a risk profile for the vulnerable junior doctor? Ir J Med Sci 2016;185:603-609.

17. Schoenberg NE and Ravdal H. Using vignettes in awareness and attitudinal research. International Journal of Social Research Methodology 2000;3(1):63-74

18. Gould D. Using vignettes to collect data for nursing research studies: how valid are the findings? J Clin Nurs 1996;5(4):207-212

19. Wilson $J$ and While AE. Methodological issues surrounding the use of vignettes in qualitative research. J Interprof Care 1998;12(1):79-86

20. R Development Core Team. R: A Language and Environment for Statistical Computing. R Foundation for Statistical Computing, Vienna, Austria. R Foundation for Statistical Computing, Vienna. 2014 http://www.R-project.org/. accessed $\underline{12 / 10 / 2019 .}$

21. Van Hamel $C$ and Jenner LE. Prepared for practice? A national survey of UK foundation doctors and their supervisors. Med Teach 2015;37(2):181-188.

22. Dean BJ and Duggleby PM. Foundation doctors' experience of their training: a questionnaire study. JRSM Short Rep 2013;4:1-7.

23. Tasker $F$, Dacombe $P$, Goddard AF et al. Improving core medical training-innovative and feasible ideas to better training. Clin Med 2014;14(6):612-617.

24. Wall D, Bolshaw A, and Carolan J. From undergraduate medical education to preregistration house officer year: how prepared are students? Med Teach 2006;28(5):435-439.

25. Armstrong $D$ and Ashworth $M$. When questionnaire response rates do matter: $a$ survey of general practitioners and their views of NHS changes. $\mathrm{Br} J$ Gen Pract 2000;50(455):479-480.

26. General Medical Council. The state of medical education and practice in the UK. 2018

27. General Medical Council. Outcomes for Graduates. 2018. https://www.gmcuk.org/education/standards-guidance-and-curricula/standards-andoutcomes/outcomes-for-graduates accessed 12/10/2019.

28. Miles S, Kellet J and Leinster SJ. Medical graduates' preparedness to practice: a comparison of undergraduate medical school training. BMCMed Educ 2017;17(33).

29. Hundert EM, Douglas-Steele D and Bickel J. Context in medical education: the informal ethics curriculum. Med Educ 1996;30(5):353-364.

30. Roland D, Matheson D, Coats T et al. A qualitative study of self-evaluation of junior doctor performance: is perceived 'safeness' a more useful metric than confidence and competence? BMJ Open 2015. 5:e008521.doi:10.1136/bmjopen-2015-008521.

31. Friedman CP, Gatti GG, Franz TM et al. Do Physicians Know When Their Diagnoses Are Correct? Implications for Decision Support and Error Reduction. J Gen Intern Med 2005;20: 334-339.

32. Berner ES and Graber NL. Overconfidence as a Cause of Diagnostic Error in Medicine. The American Journal of Medicine 2008;121(5A):S2-S23.

33. Stirrat GM. Reflections on learning and teaching medical ethics in UK medical schools. J Med Ethics 2015;41:8-11 
34. Campbell AV, Chin J, Voo T-C. How do we know that ethics education produces ethical doctors? Med Teach 2007;29:431-6

35. Kong WM. What is good medical ethics? A clinician's perspective. J Med Ethics 2015;41:79-82

36. Bowman D. What is it to do good medical ethics? Minding the gap(s). J Med Ethics 2015;41:60-63

37. Branch WT and George M. Reflection-Based Learning for Professional Ethical Formation. AMA J Ethics 2017;19(4):349-356

38. de Zuleta PC. Suffering, compassion and 'doing good medical ethics'. J Med Ethics 2015;41:87-90

39. Hafferty FW and Franks R. The hidden curriculum, ethics teaching and the structure of medical education. Acad Med 1994;69:861-7

40. McDougall R. Combating junior doctors" "4am logic": a challenge for medical ethics education. J Med Ethics 2009;35:203-206

41. Helmich E, Diachun L, Joseph R et al. 'Oh my God, I can't handle this!': trainees' emotional responses to complex situations. Med Ed 2018;52:201-215 